\title{
Delayed diagnoses of mitochondrial cytopathies in patients presenting with end stage kidney disease: two case reports
}

\author{
Tayeba Roper ${ }^{1 *}$ (D) Mark Harber ${ }^{2}$, Gareth Jones², Robert D. S. Pitceathly ${ }^{3}$ and Alan D. Salama²
}

\begin{abstract}
Background: Up to one third of patients on renal replacement programmes have an unknown cause of kidney disease, and the diagnosis may only be established following renal transplantation when the disease recurs or if new extra-renal symptoms develop.

Case presentation: We present two patients who presented with progressive chronic kidney disease of unknown cause. Both patients underwent successful renal transplantation but subsequently developed multisystem abnormalities, and were ultimately diagnosed with mitochondrial cytopathy 10-15 years following transplantation.

Conclusions: Mitochondrial cytopathies are rare inborn errors of metabolism that should be considered in adults with renal impairment, especially in those with a family history of kidney or other multisystem disease. The widespread availability of genetic testing provides the potential for earlier diagnoses, thereby enhancing management decisions, anticipation of complications, avoidance of mitotoxic drugs, and informed prognosis prediction.
\end{abstract}

Keywords: End stage renal disease, Mitochondrial cytopathies, Primary mitochondrial disease, Renal transplant, Delayed diagnoses, Inherited conditions, Multisystem disorders

\section{Background}

Mitochondrial cytopathies (MC), also known as primary mitochondrial diseases (PMD), are a rare heterogenous group of conditions, defined by sporadic or inherited mutations in either mitochondrial DNA (mtDNA) or nuclear DNA (nDNA), that encode for proteins required for mitochondrial function [1]. Consequently, $\mathrm{MC}$ may follow maternal or Mendelian inheritance patterns, depending on the location of the mutant gene [2]. During mitosis the distribution of mtDNA to daughter cells is uneven, and so cells often contain a mixture of both mutant and wild-type mtDNA [3]. Cells are therefore either homo- or heteroplasmic with regard to mutations,

\footnotetext{
* Correspondence: t.roper@nhs.net

'Department of Renal Medicine, Guy's \& St Thomas' NHS Foundation Trust, Great Maze Pond, London, UK

Full list of author information is available at the end of the article
}

i.e. contain entirely mutant mtDNA, or a varying amount of both wild-type and mutant mtDNA, respectively [4]. The overall frequency of mtDNA mutations in adults is estimated to be 1:5000 [5]. MC are often multisystem disorders and frequently affect organs or tissues with high metabolic demand, such as the brain, heart and skeletal muscle [4, 6]. MC can present as Mitochondrial Cytopathy Syndromes (MCS) affecting multiple organs, with certain clinical features occurring in clusters. Several different MCS have been reported (Table 1), however the majority of MC do not fall within these clinical entities [10]. Furthermore, different genotypes can present with the same phenotype (Table 1), which may be related to different penetrance associated with mtDNA heteroplasmy.

MC have increasingly been recognised to cause renal disease. This is unsurprising, given the high level of 
Table 1 Summary of mitochondrial cytopathy syndromes frequently associated with renal phenotypes

\begin{tabular}{|c|c|c|c|c|}
\hline MCS & Clinical Characteristics & Renal Phenotype & Genotype & Reference \\
\hline Kearns-Sayre Syndrome (KSS) & $\begin{array}{l}\text { Progressive external } \\
\text { ophthalmoplegia, } \\
\text { Retinal Pigmentary } \\
\text { degeneration, } \\
\text { Progressive myopathy, } \\
\text { Cerebellar ataxia, } \\
\text { Cardiomyopathy, } \\
\text { Heart block }\end{array}$ & $\begin{array}{l}\text { Barter-like syndrome, RTA, } \\
\text { Fanconi syndrome, Severe } \\
\text { tubulopathy }\end{array}$ & $\begin{array}{l}\text { Single large-scale } \\
\text { mtDNA deletions }\end{array}$ & {$[1,6]$} \\
\hline $\begin{array}{l}\text { Mitochondrial Encephalopathy, } \\
\text { Lactic acidosis and Stroke-like } \\
\text { Episodes (MELAS) }\end{array}$ & $\begin{array}{l}\text { Stroke-like episodes } \\
\text { (hemiparesis, hemianopia, } \\
\text { cortical blindness), Epilepsy, } \\
\text { Dementia, Lactic acidaemia, } \\
\text { Recurrent headaches, } \\
\text { Diabetes, Sensorineural } \\
\text { hearing loss, Short stature }\end{array}$ & FSGS, TIN & $\begin{array}{l}\text { Mutations in mtDNA, } \\
\text { most commonly } \\
\text { m.3243A>G }\end{array}$ & {$[2,7,8]$} \\
\hline $\begin{array}{l}\text { Myoclonus Epilepsy and } \\
\text { Ragged Red Fibres (MERRF) }\end{array}$ & $\begin{array}{l}\text { Myoclonus, Epilepsy, } \\
\text { Cerebellar ataxia, } \\
\text { Sensorineural hearing } \\
\text { loss, Myopathy, Optic } \\
\text { atrophy, Short stature, } \\
\text { Dementia } \\
\text { Muscle biopsy - ragged } \\
\text { red fibres }\end{array}$ & $\begin{array}{l}\text { FSGS, Chronic TIN, Cystic } \\
\text { renal disease ( } 1 \text { case) }\end{array}$ & $\begin{array}{l}\text { Mutations in mtDNA, most } \\
\text { commonly m.8344A>G }\end{array}$ & {$[2,9]$} \\
\hline $\begin{array}{l}\text { Leber Hereditary Optic } \\
\text { Neuropathy (LHON) }\end{array}$ & $\begin{array}{l}\text { Visual loss with optic } \\
\text { atrophy, Wolff-Parkinson-White } \\
\text { syndrome, Multiple } \\
\text { sclerosis-like disease }\end{array}$ & $\mathrm{TIN}$ & $\begin{array}{l}\text { Mutations in mtDNA, } \\
\text { most commonly m. } \\
11778 \mathrm{G}>\mathrm{A}, \mathrm{m} .3460 \mathrm{G}>\mathrm{A} \text {, } \\
\text { m.14484T }>C\end{array}$ & {$[6,10-12]$} \\
\hline $\begin{array}{l}\text { Maternally Inherited } \\
\text { Diabetes \& Deafness (MIDD) }\end{array}$ & $\begin{array}{l}\text { Sensorineural hearing loss, } \\
\text { Diabetes, Macular retinal } \\
\text { dystrophy, Myopathy, Short } \\
\text { stature, Gastrointestinal disease }\end{array}$ & FSGS & $\begin{array}{l}\text { Point mutations in mtDNA, } \\
\text { most commonly m.3243A>G }\end{array}$ & [13] \\
\hline Leigh Disease & $\begin{array}{l}\text { Developmental delay, Ataxia, } \\
\text { Dementia, Dystonia, Seizures, } \\
\text { Vomiting, Respiratory failure }\end{array}$ & Fanconi syndrome & $\begin{array}{l}\text { Mutations in mtDNA and } \\
\text { nDNA, most commonly } \\
\text { involvilng complex I genes }\end{array}$ & [1] \\
\hline Pearson Syndrome & $\begin{array}{l}\text { Severe anaemia, Neutropenia, } \\
\text { Sensorineural hearing loss, } \\
\text { Thrombocytopenia, Exocrine } \\
\text { pancreatic insufficiency } \\
\text { Bone marrow biopsy - ring } \\
\text { sideroblasts }\end{array}$ & $\begin{array}{l}\text { Tubulopathy, FSGS, } \\
\text { Crescentic GN, Mesangial } \\
\text { proliferation }\end{array}$ & $\begin{array}{l}\text { Single large-scale mtDNA } \\
\text { deletions }\end{array}$ & [7] \\
\hline COQ10 Biosynthesis Defects & $\begin{array}{l}\text { Cerebellar Ataxia, Isolated } \\
\text { myopathy, Encephalopathy, } \\
\text { Myoglobinuria, Sensorineural } \\
\text { hearing loss }\end{array}$ & $\begin{array}{l}\text { Nephrotic syndrome } \\
\text { (FSGS), Tubulopathy }\end{array}$ & $\begin{array}{l}\text { Mutations in } 8 \text { nuclear } \\
\text { encoded mitochondrial } \\
\text { genes; PDSS1/2, COQ2/4/6/9, } \\
\text { ADCK3/4 }\end{array}$ & {$[2,14]$} \\
\hline
\end{tabular}

metabolic activity within the kidneys [4, 7]. The majority of $\mathrm{MC}$ with renal manifestations present in childhood, but can also present in adults [1]. Diagnosing MC can be challenging, given their heterogeneity, but should be considered when multiple systems are involved or if there is a positive family history [3, 10]. Renal histology may show the presence of dysmorphic mitochondria on electron microscopy [2, 3]. However, MC are generally diagnosed through measurement of mitochondrial oxidative phosphorylation enzyme activities, alongside genetic testing. In the case of mtDNA, analysis of multiple tissue types, including blood leucocytes, urinary epithelial cells and skeletal muscle tissue, is often required $[2,6]$.
Here, we report two patients presenting with renal disease in whom the diagnosis of $\mathrm{MC}$ was made several years after their initial presentations with end stage renal disease (ESRD), following the development of progressive, nonrenal, multisystem manifestations of mitochondrial dysfunction.

\section{Case presentations}

\section{Case 1}

A 22-year-old woman was referred to her local renal unit for assessment of hypertension and advanced renal impairment, with a serum creatinine of $500 \mu \mathrm{mol} / \mathrm{l}$. She had a normal birth and childhood development. Her 
medical history was unremarkable, except for sensorineural deafness, requiring hearing aids. There was no family history of kidney disease. Investigations revealed a negative autoimmune screen, including a negative ANCA. She proceeded to a renal biopsy, which demonstrated diffuse segmental sclerosis in all glomeruli, marked tubular atrophy, interstitial fibrosis and chronic inflammation. Small vessels were constricted with some fibrinoid change in the walls. This was interpreted as being due to a pauci-immune ANCA-negative vasculitis. She received 3 months of cyclophosphamide and prednisolone, followed by azathioprine and prednisolone.

Following a rapid and progressive decline in kidney function, she was established on peritoneal dialysis. Two years later she underwent a living unrelated donor renal transplant, achieving excellent renal function with creatinine between 90 and $100 \mu \mathrm{mol} / \mathrm{l}$ within 2 weeks after transplantation. After 1 year she developed post transplantation diabetes mellitus (PTDM) and was commenced on long acting insulin, with subsequent addition of metformin. She later developed amenorrhea and dizziness.

Fifteen years post renal transplantation she was assessed by an ophthalmologist, following a deterioration in vision, who diagnosed retinal atrophy. She subsequently developed cognitive decline associated with cerebral atrophy on brain MRI. As a result of the neurological symptoms and signs, and in view of the retinal abnormalities, further genetic testing was undertaken. Restriction fragment length polymorphism of mtDNA extracted from blood leukocytes and urinary epithelial cells confirmed the m.3243A $>$ G mutation in MT-TL1 at 21 and 14\% mutant loads, respectively.
Maternal screening was declined. The patient was commenced on Co-enzyme Q10 supplementation. Renal function has remained stable with creatinine between 75 and $90 \mu \mathrm{mol} / \mathrm{l}$ during the 22 years following post transplantation. She had no vasculitis related illness throughout her prolonged follow up, suggesting the $\mathrm{MC}$ was the likely cause of her ESRD. Case 1 is summarised in Fig. 1.

\section{Case 2}

A 31-year-old woman with a background of Asperger's syndrome, thyroid goitre, aortic and mitral valve regurgitation, and sensorineural deafness, presented with ESRD. There was no family history of renal disease. At the time of presentation an acute renal immunology screen was negative and ultrasound scan demonstrated bilateral small, smooth kidneys. Renal biopsy was therefore not possible and she was commenced on haemodialysis. Five months later she received a living-related donor renal transplant from her mother. Graft function following transplantation was excellent, with a creatinine that reached a nadir of $88 \mu \mathrm{mol} / \mathrm{l}$ after 4 weeks and stabilised over a 10 year period at $110 \mu \mathrm{mol} / \mathrm{l}$.

Two years following transplantation the patient developed impaired glucose tolerance, treated with dietary modification. Three years later she developed diabetic ketoacidosis, requiring hospital admission, and was commenced on insulin therapy. Four years post transplantation she was hospitalised with an acute psychotic episode for which she commenced Olanzapine and Mirtazepine. A number of admissions followed with deterioration in mental health. Six years following the transplant there was a gradual reduction in mobility and she was investigated by neurologists who performed a

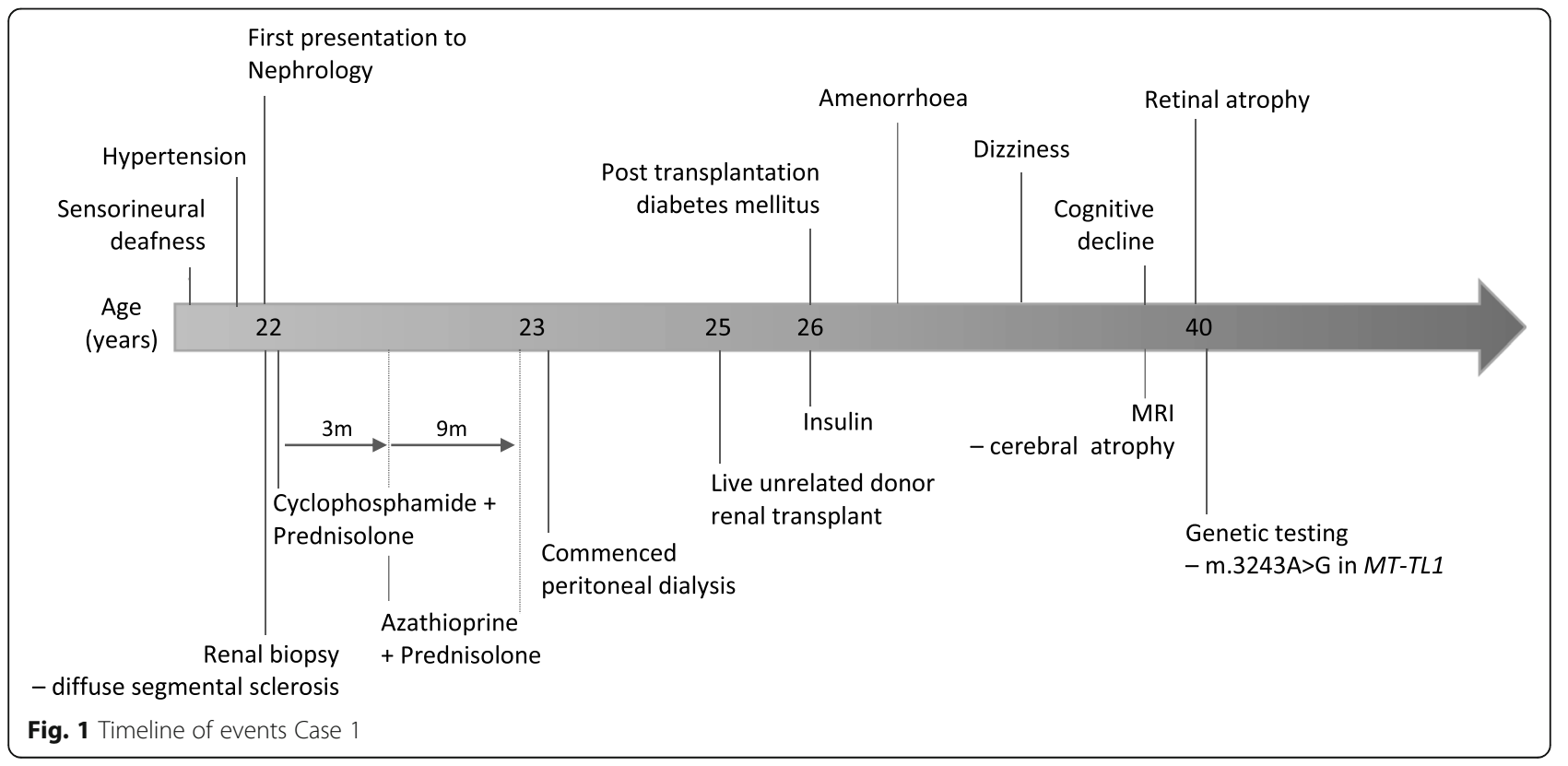


muscle biopsy and genetic testing. Muscle histology revealed mild myopathic changes with no specific features of mitochondrial disease. Next generation sequencing of mtDNA extracted from blood leukocytes, cultured fibroblasts and skeletal muscle tissue confirmed the presence of the pathogenic m.8618dup in MT-ATP6 at 20, 45 and $65 \%$ mutant loads, respectively [15]. The mutation was detected in other maternal relatives, albeit at lower levels (Fig. 2). She has since developed cataracts, which required removal, retinal thinning and optic atrophy, but no evidence of diabetic retinopathy. Case 2 is summarised in Fig. 3, and previously reported in [15].

\section{Discussion and conclusions}

Renal complications of MC are uncommon, but can present in several ways. The most frequent renal manifestation in children is tubulointerstitial nephritis (TIN) [11], while in adults the presence of proximal tubular dysfunction is more common [1]. Tubular defects range from mild tubular disease (e.g. isolated hypomagnesiaemia, hypercalcuria or renal tubular acidosis) to a complete Fanconi syndrome [2]. However, tubular defects may be overlooked in the context of other, more severe, organ involvement $[7,16]$. Glomerular disease has also been reported, generally with focal segmental glomerulosclerosis (FSGS) and associated proteinuria. Rarely, MC have been found to cause chronic TIN and cystic renal disease [2]. In both cases presented, the exact mechanism of renal injury remains unknown, due to the advanced stage of renal impairment at the time of presentation. The late onset presentation of renal disease in these two patients, might have been a result of genetic drift of mtDNA heteroplasmy over time. In rapidly dividing cells, such as blood leukocytes, there is a reduction in mutant mtDNA heteroplasmy over time, while the opposite is thought to occur in post-mitotic cells [17]. A clinical phenotype is only observed when the mutant mtDNA load exceeds a mutation specific biochemical 'threshold' [2, 3]. Interestingly, Case 2 exhibited a lower mutant load in urinary epithelial cells than blood, despite the former usually correlating more closely with post-mitotic tissues, such as muscle tissue. It is possible the donor renal transplant contributed towards the lower than expected level of mutant mtDNA, compared to native kidneys and bladder derived cells. However, further genetic testing of urinary epithelial cells pre- and post-transplant would be required to investigate this finding further.

As demonstrated in both cases, the vast array of affected organ systems and different clinical features of MC and MCS presenting over a protracted time period, make diagnosis of these conditions a challenge. This is further complicated by the fact that many routine investigations for $\mathrm{MC}$ can present with variable, including normal, findings even in the presence of disease. Specific routine investigations often include biochemical tests to quantify creatine kinase, blood glucose, serum lactate and pyruvate. These can all be raised in MC, however levels can vary with different phenotypes and may be normal in some. Skeletal muscle biopsy was previously

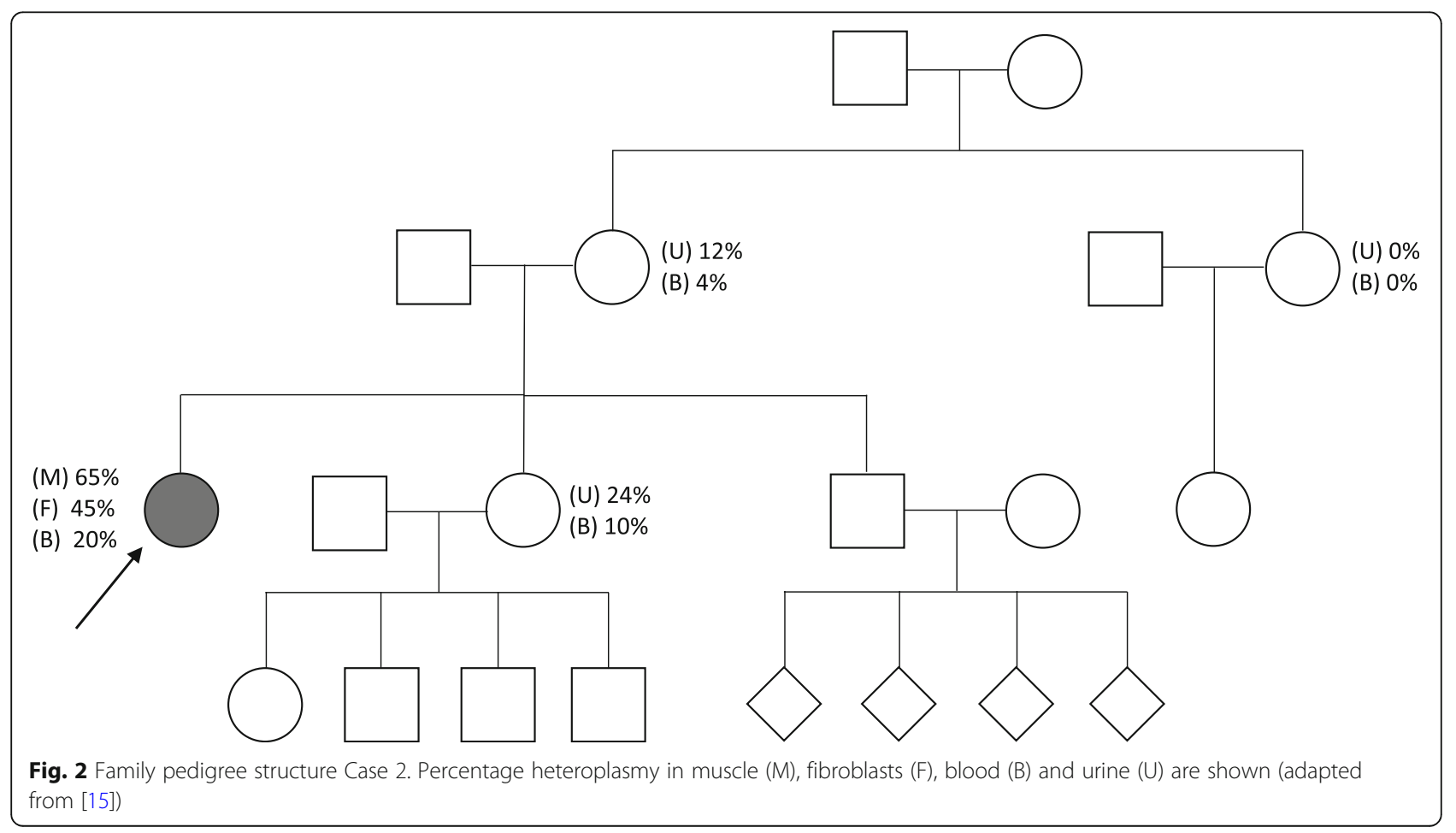




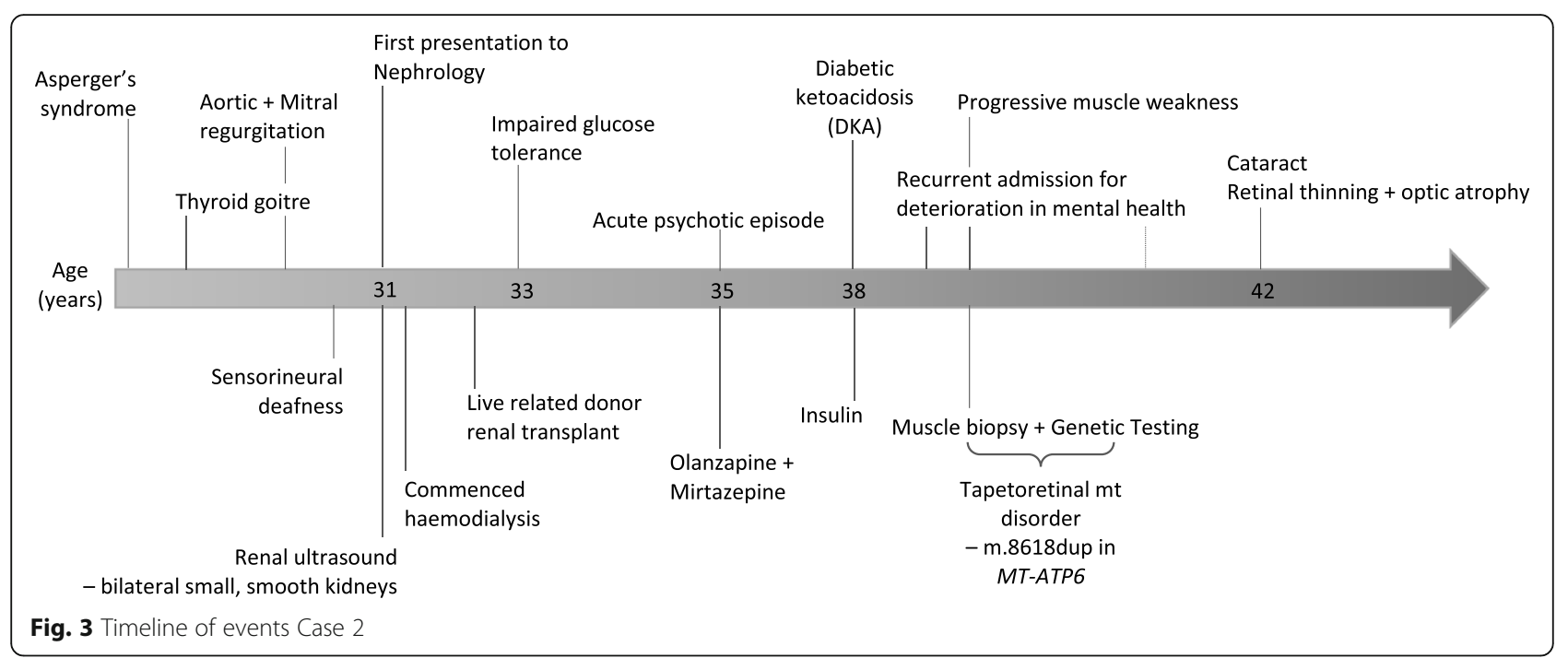

the gold standard investigation for identifying MC. Modified Gomori trichrome staining can reveal the abnormal accumulation of sub-sarcolemmal mitochondria, giving the typical 'Ragged Red Fibre' appearance on microscopy. Electron microscopy can be used to visualise mitochondria and determine morphology, presence of abnormal inclusions and pleomorphic mitochondria. Furthermore, analysis of enzyme activity from biopsy specimens can identify specific deficiencies of complexes of the respiratory chain [18]. As with biochemical tests, and as demonstrated in Case 2, muscle biopsy results can also be normal even in the presence of disease. Case 1 highlights how many MC are now diagnosed without the need for muscle biopsy. Following advances in nextgeneration sequencing, genetic analysis of nDNA extracted from blood, or mtDNA extracted from blood leukocytes, urine epithelial cells or affected tissues, can identify mutations responsible for MC [19]. Many commercial kits are now available to identify known mutations associated with $\mathrm{MC}$, alternatively whole genome sequencing can be used to identify previously unknown mutations [20].

Management of $\mathrm{MC}$ requires a multidisciplinary team approach, and often involves supportive care alongside targeted treatment of organ-specific complications (e.g. renal replacement therapy for ESRD) [21]. Diseasespecific treatments are also available for certain MCS, and often involve replacement of specific components involved in mitochondrial function. Coenzyme Q10 is one such component of the respiratory chain. Supplementation with Coenzyme Q10, as in Case 1, and more recently Coenzyme Q10 analogues (e.g. Idebenone), is often used in patients with a MC which may cause a deficiency of this enzyme, and can result in a delay in the progression of disease. However, timely initiation of therapy is key in order to observe any benefit. Similarly, supplementation with other antioxidants or cofactors involved in the respiratory chain, such as; L-arginine, Lcarnitine, thiamine, creatine phosphate and vitamins B2, $\mathrm{C}$ and $\mathrm{E}$, may also provide some clinical benefit [22]. In contrast, confirming a diagnosis of a $\mathrm{MC}$ can also allow for appropriate avoidance of medications which may exacerbate disease. These include certain anaesthetic agents (e.g. propofol) which may depress mitochondrial function, substances metabolised by mitochondria (e.g. sodium valproate), inhibitors of the respiratory chain (e.g. metformin, statins) and mitochondrial protein synthesis inhibitors (e.g. aminoglycosides, tetracyclines) [20]. Overall management of these conditions remains largely supportive. Further advances in therapies continue to be investigated, and include the use of gene therapy, enzyme replacement and methods to stimulate mitochondrial proliferation and alter heteroplasmy [20, $22]$. In both the cases, earlier diagnosis may have allowed for more timely initiation of appropriate management, including avoidance of medications such as metformin. Although it will remain unknown, this could have potentially impacted on the development of extra-renal disease manifestations.

The cases presented are typical of many patients with an underlying $\mathrm{MC}$, in that they develop disorders of multiple organ systems over time, with no specific symptoms pointing towards an underlying common cause. Diabetes is one such feature which is found to be present in many patients with $\mathrm{MC}$, particularly those with $\mathrm{m} .3243 \mathrm{~A}>\mathrm{G}$ mutations. The clinical picture was complicated in both cases, as both were thought to have developed PTDM. PTDM is common, occurring in up to one third of non-diabetic patients following transplantation [23]. Many studies have identified single nucleotide polymorphisms, previously linked to both type 1 and type 2 diabetes mellitus, to be associated with an 
increased risk of developing PTDM, none of these however are associated with mtDNA or mitochondrial function [24]. Studies have shown that, although many patients with MC develop diabetes in childhood, the heteroplasmic nature of the mitochondrial mutation within cells means diabetes can also develop later in life. Such patients have been shown to develop progressive loss of insulin secretion from pancreatic $\beta$-cells in response to glucose stimulation, as opposed to insulin resistance at the cellular level [25]. As a result, these patients often become insulin-dependent. The use of Metformin should be avoided due to the risk of developing severe lactic acidosis, as metformin is known to inhibit components of the respiratory chain [25]. It is possible that in both cases presented the development of diabetes was related purely to the underlying MC. Alternatively it could be that there was a low level of heteroplasmy within the pancreatic $\beta$-cells of these patients, but with the addition of immunosuppressant medication (steroids and calcineurin inhibitors) post-transplantation, they were tipped into a diabetic phenotype.

Up to as many as $28 \%$ of patients established on renal replacement therapy (RRT) have no identified cause of ESRD [26, 27]. Furthermore, many more patients, have a presumed diagnosis made with no biopsy evidence of the underlying pathology. As demonstrated by these two cases, diagnosing $\mathrm{MC}$ can be a challenge. In Case 1, the correct diagnosis was not initially made, despite renal biopsy, as this showed non-specific features of diffuse segmental sclerosis with interstitial fibrosis and tubular atrophy. The presence of segmental sclerosing lesions on renal biopsy is a common feature observed in MC but can also be seen secondary to a host of other aetiologies $[28,29]$. As discussed above, further diagnostic delay occurred in both patients, as the PTDM was presumed to be exclusively due to immunosuppressive therapy, and not the common presenting feature of many MCS [30]. It was not until both patients developed progressive neurological features that an all-encompassing, alternative diagnosis was considered and investigated. Clinicians should consider a possible underlying diagnosis of a MC particularly in patients with no identified cause of ESRD, who develop diabetes and have symptoms relating to two or more other organ systems. Suspicions of an underlying MC may be further heightened in those with a strong family history of renal disease and/or diabetes, and in those with symptoms suggestive of an underlying muscle or neurological disorder [19].

Although relatively rare, $\mathrm{MC}$ are increasingly recognised as a cause of renal impairment and ESRD. MC should be considered when assessing patients presenting with renal disease of unknown aetiology, particularly if a family history of renal impairment exists, and/or if there is evidence or development of multi-system disease.
Normal investigation results do not necessarily exclude a diagnosis of a MC. Consequently, if there is a high degree of clinical suspicion, referral to a specialist centre for further assessment and genetic testing should be considered.

\section{Abbreviations \\ ESRD: End stage renal disease; FSGS: Focal segmental glomerulosclerosis; MC: Mitochondrial cytopathies; MCS: Mitochondrial cytopathy syndromes; mtDNA: Mitochondrial deoxyribonucleic acid; nDNA: Nuclear deoxyribonucleic acid; PMD: Primary mitochondrial diseases; PTDM: Post transplantation diabetes mellitus; RRT: Renal replacement therapy; TIN: Tubulointerstitial nephritis; tRNA: Transfer ribonucleic acid}

\section{Acknowledgements}

Not applicable.

\section{Authors' contributions}

TR wrote the introduction and discussion sections, and contributed to the case descriptions. ADS wrote the case descriptions and contributed to the overall final structure. RDSP provided information regarding neurological assessment of the cases. MH, GJ, RDSP and ADS reviewed the final edit. All authors read and approved the final manuscript.

\section{Funding}

Part of this work was undertaken in the University College London Hospitals/ University College London Queen Square Institute of Neurology sequencing facility, which received a proportion of funding from the Department of Health's National Institute for Health Research Biomedical Research Centres funding scheme. The clinical and diagnostic 'Rare Mitochondrial Disorders' Service in London is funded by the UK NHS Highly Specialised Commissioners. RDSP is supported by a Medical Research Council Clinician Scientist Fellowship (MR/S002065/1).

\section{Availability of data and materials}

The datasets generated and/or analysed during the current study are available in the NCBI dbsnp repository, https://www.ncbi.nlm.nih.gov/clinvar/ variation/9589/ and https://www.ncbi.nlm.nih.gov/clinvar/variation/9648/.

Ethics approval and consent to participate

Not applicable.

\section{Consent for publication}

Written consent for publication was obtained from both patients reported herein.

\section{Competing interests}

The authors declare that they have no competing interests.

\section{Author details}

'Department of Renal Medicine, Guy's \& St Thomas' NHS Foundation Trust, Great Maze Pond, London, UK. ' UCL Department of Renal Medicine, Royal Free Hospital, Pond Street, Hampstead, London, UK. ${ }^{3}$ Department of Neuromuscular Diseases, UCL Queen Square Institute of Neurology and The National Hospital for Neurology and Neurosurgery, London, UK.

Received: 7 July 2019 Accepted: 3 August 2020

Published online: 24 August 2020

\section{References}

1. Niaudet $P$, Rötig A. The kidney in mitochondrial cytopathies. Kidney Int. 1997:51(4):1000-7.

2. Emma F, et al. Renal involvement in mitochondrial cytopathies. Pediatr Nephrol. 2012;27(4):539-50.

3. Emma F, Salviati L. Mitochondrial cytopathies and the kidney. Nephrol Ther. 2017;13(Suppl 1):S23-8.

4. O'Toole JF. Renal manifestations of genetic mitochondrial disease. Int J Nephrol Renovasc Dis. 2014;7:57-67.

5. Gorman GS, et al. Prevalence of nuclear and mitochondrial DNA mutations related to adult mitochondrial disease. Ann Neurol.2015;77(5):753-9. 
6. Taylor RW, Turnbull DM. Mitochondrial DNA mutations in human disease. Nat Rev Genet. 2005;6(5):389-402.

7. Emma F, et al. Mitochondrial dysfunction in inherited renal disease and acute kidney injury. Nat Rev Nephrol. 2016;12(5):267-80.

8. Morrow KL, et al. Increased risk of renal dysfunction with percutaneous mechanical thrombectomy compared with catheter-directed thrombolysis. J Vasc Surg. 2017;65(5):1460-6.

9. Lorenzoni PJ, et al. When should MERRF (myoclonus epilepsy associated with ragged-red fibers) be the diagnosis? Arq Neuropsiquiatr. 2014;72(10): 803-11.

10. Finsterer J, Scorza FA. Renal manifestations of primary mitochondrial disorders. Biomed Rep. 2017;6(5):487-94.

11. Thieblemont N, Witko-Sarsat V, Ariel A. Regulation of macrophage activation by proteins expressed on apoptotic neutrophils: subversion towards autoimmunity by proteinase 3. Eur J Clin Invest. 2018;48(2):e12990. https:// doi.org/10.1111/eci.12990.

12. Rahman SH, Hall AM. Mitochondrial disease - an important cause of endstage renal failure. Pediatr Nephrol. 2013;28:357-61.

13. Naing A, et al. Maternally inherited diabetes and deafness (MIDD): diagnosis and management. J Diabetes Complicat. 2014;28(4):542-6.

14. Doimo M, et al. Genetics of coenzyme q10 deficiency. Mol Syndromol. 2014; 5(3-4):156-62

15. Bugiardini $\mathrm{E}$, et al. Expanding the molecular and phenotypic spectrum of truncating MT-ATP6 mutations. Neurol Genet. 2020;6(1):e381.

16. Emma F, et al. Renal mitochondrial cytopathies. Int J Nephrol. 2011;2011: 609213.

17. Rahman S, et al. Decrease of 3243 A-- $>$ G mtDNA mutation from blood in MELAS syndrome: a longitudinal study. Am J Hum Genet. 2001;68(1):238-40.

18. Bourgeois JM, Tarnopolsky MA. Pathology of skeletal muscle in mitochondrial disorders. Mitochondrion. 2004;4(5-6):441-52.

19. Davison JE, Rahman S. Recognition, investigation and management of mitochondrial disease. Arch Dis Child. 2017;102(11):1082-90.

20. Paiva Coelho M, Martins E, Vilarinho L. Diagnosis, management, and followup of mitochondrial disorders in childhood: a personalized medicine in the new era of genome sequence. Eur J Pediatr. 2019;178(1):21-32.

21. Davis RL, Liang C, Sue CM. Mitochondrial diseases. Handb Clin Neurol. 2018; 147:125-41.

22. Gorman GS, et al. Mitochondrial diseases. Nat Rev Dis Primers. 2016;2:16080.

23. Mourad G, et al. Incidence of Posttransplantation diabetes mellitus in De novo kidney transplant recipients receiving prolonged-release Tacrolimusbased immunosuppression with 2 different corticosteroid minimization strategies: ADVANCE, A Randomized Controlled Trial. Transplantation. 2017; 101(8):1924-34.

24. Shivaswamy V, Boerner B, Larsen J. Post-transplant diabetes mellitus: causes, treatment, and impact on outcomes. Endocr Rev. 2016;37(1):37-61.

25. Maassen JA, et al. Mitochondrial diabetes molecular mechanisms and clinical presentation. Diabetes. 2004;53:S103-9.

26. Lyons PA, et al. Genetically distinct subsets within ANCA-associated vasculitis. N Engl J Med. 2012;367(3):214-23.

27. Byrne C, Caskey F, Castledine C, Davenport A, Dawnay A, Fraser S, Maxwell H, Medcalf JF, Wilkie M, Williams AJ. 20th Annual Report of the Renal Association. NEPHRON. 2018;139.

28. Doleris $L M$, et al. Focal segmental glomerulosclerosis associated with mitochondrial cytopathy. Kidney Int. 2000;58(5):1851-8.

29. Fogo AB. Causes and pathogenesis of focal segmental glomerulosclerosis. Nat Rev Nephrol. 2015;11(2):76-87.

30. Maassen JA. Mitochondrial diabetes: pathophysiology, clinical presentation, and genetic analysis. Am J Med Genet. 2002;115(1):66-70.

\section{Publisher's Note}

Springer Nature remains neutral with regard to jurisdictional claims in published maps and institutional affiliations.

Ready to submit your research? Choose BMC and benefit from:

- fast, convenient online submission

- thorough peer review by experienced researchers in your field

- rapid publication on acceptance

- support for research data, including large and complex data types

- gold Open Access which fosters wider collaboration and increased citations

- maximum visibility for your research: over $100 \mathrm{M}$ website views per year

At BMC, research is always in progress.

Learn more biomedcentral.com/submissions 